\title{
Turismo, história oral e velhice: o contexto do patrimônio cultural rural paulista (São Paulo, Brasil)
}

\author{
Tourism, oral history an old age: the context of rural São Paulo (Brasil) cultural \\ heritage
}

\author{
Lívia Morais Garcia Lima (LIMA, L. M. G.)
}

RESUMO - Neste artigo se teve por objetivo refletir sobre a contribuição da história oral nos estudos sobre o patrimônio e as ações de educação patrimonial em fazendas históricas paulistas (São Paulo, Brasil). As questões aqui problematizadas fazem parte de uma pesquisa concluída em 2010, onde o patrimônio estava sendo explorado como espaço turístico educacional dentro de uma visão da educação não formal no contexto rural, voltado para o público idoso, de formações educacionais e classes sociais diversas. Esse processo foi realizado a partir de uma metodologia de caráter qualitativo (História Oral) com ênfase em duas técnicas: a entrevista aberta e o depoimento temático. A pesquisa sobre o patrimônio cultural rural paulista se tornou um trabalho sobre a utilização dos bens culturais como fonte de lazer e turismo, possibilitando um exercício de sensibilização para a valorização dos espaços rurais, a partir da análise das representações dos sujeitos e seus papéis, o imaginário rural, e da decodificação dos valores existentes naqueles espaços.

Palavras-chave: Velhice; História oral; Turismo; Patrimônio.

ABSTRACT - This article aims to reflect on the contribution of oral history in studies on equity shares and equity in education paulistas historic farms. Problematic issues here are part of a recently completed research, where the heritage is explored as an educational tourist space within a vision of non-formal education in the rural setting, facing the elderly public, educational backgrounds and different social classes. This process was carried out from a qualitative methodology (Oral History) with emphasis on two techniques: the open interview and the thematic statement. Research on the São Paulo countryside cultural heritage becomes a paper on the use of cultural property as a source of recreation and tourism, allowing an exercise in awareness of the value of rural areas, by analyzing the subjects' representations and their roles, the rural, and decoding of the existing values in that space imagery.

Key words: Old age; Oral history; Tourism; Heritage.

\footnotetext{
* Formação: Graduação em Turismo (Bacharelado) pela Universidade Estadual Paulista (UNESP), Mestrado em Gerontologia pela Universidade Estadual de Campinas (UNICAMP). Doutorado em Educação pela Faculdade de Educação - UNICAMP na área de Ciências Sociais na Educação - DECISE e bolsista da Fundação de Amparo a Pesquisa do Estado de São Paulo (FAPESP). Realizou estágio de pesquisa no exterior na Universidade Pontifícia de Salamanca (Espanha), com bolsa BEPE/FAPESP entre 2013 e 2014. Endereço físico para correspondência: Rua Renato Reis, 176, casa dos fundos (Jardim América). CEP: 13.084-445 - Campinas/SP - Brasil. Email: liviamglima@ gmail.com
} 


\section{INTRODUÇÃO}

Neste artigo se teve por objetivo refletir sobre a contribuição da história oral nos estudos sobre o patrimônio e as ações de educação patrimonial em fazendas históricas paulistas (São Paulo, Brasil). Na pesquisa ${ }^{1}$, o patrimônio foi explorado como espaço turístico educacional dentro de uma visão de educação patrimonial não formal no contexto rural, através de um turismo cultural em espaço rural que explicasse e contextualizasse a relação urbano/rural para os idosos que visitavam as fazendas.

Tem-se observado que a cidade, independente de sua localização ou de seu tamanho, constrói-se pela acumulação de imagens múltiplas e variadas, reais e imaginadas, que atraem e criam o desejo de experimentar o seu charme, de penetrar e de descobrir os seus mistérios. Este poder de atração da cidade predispõe ao turismo (ALMEIDA, 2010, p. 11).

Optou-se por assumir o termo velho ou idoso pelo fato destas categorias delimitarem com maior clareza as representações pelas quais a velhice vem passando, enquanto o tratamento como terceira idade, melhor idade, idade de ouro, idade legal, dentre outras, foram considerados pela autora como subterfúgios semânticos, palavras aprazíveis, tendo o propósito de encobrir um debate mais importante, que é a função social da velhice na sociedade, em que o velho é alvo do mercado consumidor crescente, como por exemplo, o mercado turístico.

O uso da designação "terceira idade" ou "melhor idade" ao invés de velhice vêm provocar um novo sentido que seria o sentido da não velhice, negando o sentido histórico da velhice como declínio, incapacidade, fragilidade e como fase de resignação às perdas da beleza e da capacidade físico-cognitiva. Essa nova sensibilidade considera a juventude como um valor dissociado à categoria etária, que deve ser preservado na vida das pessoas envelhecidas (OLIVEIRA, 2009, p. 37).

Também sobre a concepção de velhice ativa atrelada à ideia de terceira idade, Debert (1999) enfatiza o quanto essa expressão e os movimentos que se organizam em torno dela indicam mudanças radicais na forma como o envelhecimento é visto, deixando de ser compreendido como decadência física, perda de papéis sociais e

1 Dissertação de mestrado intitulada: TURISMO, CULTURA E VELHICE BEM-SUCEDIDA: contribuições para a elaboração de atividades turístico-culturais para idosos no contexto de fazendas históricas paulistas, defendida em 2010, na UNICAMP, sob orientação da Prof. Dra. Olga Rodrigues de Moraes von Simson. 
retraimento. A autora cita como exemplo o grande número de programas para a "terceira idade" no Brasil, como os grupos de convivência, as escolas abertas e as universidades. Dessa forma, considera-se estar justificado assumir o termo idoso ou velho no presente artigo.

O espaço empírico da pesquisa foi o das fazendas históricas paulistas, selecionadas pelo projeto em Políticas Públicas denominado: Patrimônio Cultural Rural Paulista: espaço privilegiado para pesquisa, educação e turismo (Oitava Chamada para o Programa de Pesquisa em Políticas Públicas - PPPP) (TOGNON, 2007). O projeto foi financiado pela Fundação de Amparo à Pesquisa do Estado de São Paulo - FAPESP, em parceria com o Centro de Memória UNICAMP, no período de 2008 a 2012, ao qual a pesquisa esteve vinculada.

O projeto PPPP/FAPESP reuniu dezoito propriedades em regiões significativas do Estado de São Paulo, sendo essas definidas pelos núcleos regionais compostos pelas cidades de Campinas, Limeira-Rio Claro, São Carlos-Araraquara, Itu, Mococa-Casa Branca e Vale do Paraíba. A Associação das Fazendas Históricas Paulistas é uma OSCIP (Organização da Sociedade Civil de Interesse Público) responsável por reunir essas propriedades históricas dos séculos XVIII, XIX, e início do século XX que trabalham com turismo no espaço rural. O projeto teve como objetivo principal disponibilizar um conjunto de instrumentos e de metodologias de gestão, de conservação e de difusão para os responsáveis por esse patrimônio cultural rural, tanto os proprietários quanto as respectivas instâncias públicas pertinentes à área da cultura, da educação e do turismo.

Segundo o então coordenador do projeto, Tognon (2007) o Patrimônio Cultural Rural pode ser definido como o conjunto de registros materiais e imateriais decorrentes das práticas, dos costumes e das iniciativas produtivas que se estabelecem, historicamente e territorialmente, na área rural.

As propriedades pesquisadas surgiram em decorrência da ocupação da região central paulista nos séculos XVIII e XIX, dados a grande diversidade de bens que formam o seu patrimônio histórico cultural e natural (TOGNON, 2007, p. 5). Essa diversidade de bens culturais se, por um lado, representa uma grande potencialidade para as atividades de pesquisa e para as ações de políticas públicas, por outro, apresenta permanentemente desafios no estabelecimento de procedimentos metodológicos que 
permitem a descoberta, a identificação, a caracterização, a análise e a descrição desses bens. Marins (2013) completa a ideia da importância dos estudos do meio rural paulista afirmando:

\begin{abstract}
Se hoje compreendermos as manifestações da arquitetura rural antes como suportes de memórias sociais e como documentos históricos sobre a vida social e material das populações brasileiras - e não apenas como monumentos que celebram uma visão cristalizada e excludente da sociedade brasileira baseada no cânone nacional -, a proteção de edificações e agenciamentos espaciais constitui imenso desafio às políticas de preservação do patrimônio cultural, especialmente no caso paulista. (MARINS, 2013, p. 164).
\end{abstract}

O autor ainda chama a atenção para que o território paulista abriga exemplares significativos de testemunhos arquitetônicos das culturas do trigo quinhentista e seiscentista, da produção de açúcar difundida durante a segunda metade do século XVIII, das fazendas de criações, da gigantesca vaga cafeicultora, das culturas de abastecimento e de ocorrências mais pontuais, como o algodão e a produção leiteira, muitas vezes ampliada e adaptada no tempo, por culturas que se sucederam.

O pesquisador responsável pelo PPPP/FAPESP, Tognon (2007), ainda ressalta que tal Patrimônio Cultural Rural possui um perfil múltiplo, em escalas e tipologias, que contemplam não só as fazendas históricas e os complexos produtivos antigos, mas também usinas e barragens para a implementação das pioneiras redes de produção e distribuição de energia elétrica do campo e da cidade, pontes, diques, ferrovias, enfim, registros edificados no território agrário que se somam aos acervos artísticos, bibliotecas, arquivos, equipamentos e máquinas, festas e arte popular, hábitos, costumes, crenças e modos de fazer.

Tognon (2003, p. 163) complementa a ideia conceituando "os bens culturais como sendo os mais importantes resultados históricos da cultura humana na constituição do seu território". Tal tema para o autor ganha, a cada dia, espaço nas políticas públicas e que aos poucos se estende pelo Brasil e se associa a programas de estímulos a polos turísticos.

Pode-se perceber a amplitude que a atividade turística possui e que, ela remete a uma série de tipologias de turismo. E a tipologia de turismo que dialoga com o patrimônio cultural se refere justamente ao turismo cultural, que estaria relacionado a todo turismo cujo principal atrativo não seja a natureza, mas algum aspecto da cultura humana. (BARRETT0, 2001, p. 57). 


\title{
1.1 EDUCAÇÃO NÃO FORMAL E SUAS POSSIBILIDADES
}

A outra face da discussão que neste projeto se estava propondo é a da educação não formal, que assim pode ser definida:

\begin{abstract}
A educação não formal, por poder lidar com outra lógica espaço-temporal, por não necessitar se submeter a um currículo definido a priori, por dar espaço para receber temas, assuntos, variedades que interessam ou sejam válidos para um público específico naquele determinado momento e que esteja participando de propostas, programas ou projetos nesse campo, faz com que cada trabalho e experimentação sejam únicos. E, por envolver profissionais e freqüentadores que podem exercitar e experimentar outro papel social, que não o representado na escola formal (como professores e alunos), contribui com uma maneira de lidar com o cotidiano, com os saberes, com a natureza e com a coletividade (SIMSON; PARK, FERNANDES, 2007, p. 13).
\end{abstract}

Complementando o conceito acima, Afonso (1989, p 78) ressalta:

A educação não formal, embora obedeça também a uma estrutura e a uma organização (distintas, porém das escolas) e possa levar a uma certificação (mesmo que não seja essa a finalidade) diverge ainda da educação formal; no que respeita à não fixação de tempos e locais e à flexibilidade na adaptação dos conteúdos de aprendizagem a cada grupo concreto.

Garcia (2009, p. 53), sobre o surgimento e o papel da educação não formal, afirma:

A educação não formal pode considerar, valorizar e reafirmar a cultura dos indivíduos nela envolvidos, incluindo educadores e educandos, fazendo com que a bagagem cultural que cada um traz seja respeitada e esteja presente no decorrer de todos os trabalhos, procurando não somente respeitar e valorizar a realidade de cada um, mas indo além, fazendo com que essa realidade perpasse todas as relações.

O termo não formal refere-se ao que não é formal, mas que também não é informal, e assim, visa enfocar o que está fora dos espaços escolares. Embora o termo indique uma contraposição ao que é formal/escolar não é neste sentido que se quis entendê-lo. Também, algo não pode ser definido por uma negação, o que mostra uma tentativa não fértil de construir um conceito de educação, por meio de uma nova terminologia. Bastaria tratar da educação em contextos múltiplos e ampliados, sob muitas formas e com variados públicos. 
Assim, salienta-se a possibilidade do desenvolvimento de uma educação não formal, não estando restrita ao espaço urbano, e que se desenvolve em espaço rural possibilitando a compreensão por parte dos educandos do contexto agrário cafeeiro paulista e do patrimônio material e imaterial por ele produzido.

Nessa perspectiva, é necessário se pensar a educação patrimonial não só como um aspecto a ser trabalhado comumente em escolas, mas também em espaços educacionais não formais, (como é o caso das fazendas históricas selecionadas nessa pesquisa) e como fonte de ativação da memória social ${ }^{2}$.

Mediante a pesquisa de campo realizada e através da análise de depoimentos, propôs-se mostrar a intersecção da memória com a vida social. A opção pela metodologia da história oral contribuiu para a construção do corpus da pesquisa, porque tratou a entrevista com os participantes como um momento de troca entre o pesquisador e o pesquisado, permitindo assim novas reflexões sobre o imaginário e o espaço rural paulista.

\section{HISTÓRIA ORAL, TURISMO E PATRIMÔNIO}

O que é história oral? É um método? Uma disciplina? Um tema novo? Na minha opinião, é uma abordagem muito mais ampla: é a interpretação da história, das sociedades e das culturas por meio da escuta e do registro da história de vida das pessoas. E a habilidade fundamental na história oral é aprender a escutar. Paul Thompson (2006, p. 12).

Davis (2003) trata o momento da entrevista como um evento interativo, uma performance que envolve as atividades de ambos: o entrevistador e o entrevistado, permitindo compreender a entrevista como uma construção reflexiva.

Uma entrevista é uma troca entre dois sujeitos: literalmente uma visão mútua. Uma parte não pode realmente ver a outra a menos que a outra possa vê-lo ou vê-la em troca. Os dois sujeitos, interatuando, não podem agir juntos a menos que alguma espécie de mutualidade seja estabelecida (PORTELLI, 1997, p. 9).

\footnotetext{
${ }^{2}$ O conceito de memória social é trabalhado a partir do conceito de Halbwachs (1990). A memória social é aquela formada pelos fatos e aspectos julgados relevantes pelos grupos dominantes e que são guardados como memória oficial da sociedade mais ampla.
} 
$\mathrm{O}$ autor ressalta que o pesquisador de campo tem um objetivo amparado em igualdade, o que não pode ser desejada no fazer, mas como condição para uma comunicação menos distorcida e um conjunto de informações menos tendenciosas. Portelli (1997, p. 10) ainda afirma que "a entrevista levanta em ambas as partes uma consciência da necessidade por mais igualdade a fim de alcançar maior abertura nas comunicações".

Assim, para se discutir a História Oral como um procedimento de pesquisa, fazse necessário inicialmente "tornar claro o significado atribuído à pesquisa, vista como forma de conhecer a realidade" (LANG, 2001, p. 91). Dessa forma, a autora defende a ideia de que:

\begin{abstract}
A História Oral constitui uma metodologia qualitativa de pesquisa voltada para o conhecimento do tempo presente; permite conhecer a realidade presente e o passado ainda próximo pela experiência e pela voz daqueles que os viveram. Não se resume a uma simples técnica, incluindo também uma postura, na medida em que seu objetivo não se limita à ampliação de conhecimentos e informações, mas visa conhecer a versão dos agentes. Permite conhecer diferentes versões sobre um mesmo período ou fato, versões estas marcadas pela posição social daqueles que os viveram e os narram (LANG, 2001, p. 96).
\end{abstract}

Thompson (2006, p. 20) ainda enfatiza a história oral como um campo interdisciplinar. "Ela não é simplesmente histórica, mas também sociológica, antropológica, pois ela se baseia nessa forma fundamental de interação humana, que transcende as disciplinas."

Durante a pesquisa foram realizadas entrevistas em cada fazenda parceira do projeto com o proprietário/a ou com o responsável pela gerência do empreendimento e com o funcionário mais antigo, vivendo na propriedade. No caso das fazendas históricas selecionadas pelo projeto em políticas públicas da PPPP/FAPESP, percebeu-se que de grandes propriedades produtoras de café ou cana, posteriormente se tornaram, pelo arrendamento de suas terras, propriedades relativamente pequenas (45 a 50 alqueires) com pouca ou nenhuma atividade agrícola. Notou-se uma clara perda de poder econômico de seus proprietários que passaram a encarar o turismo cultural e a educação patrimonial como sua fonte principal de renda.

Nos trabalhos em campo realizados nas propriedades históricas, foi feita uma rápida passagem pelo patrimônio arquitetônico preservado e escolhido um local mais 
calmo, solicitando ao proprietário que indicasse o funcionário mais antigo, ainda vivendo no local, para coletar sua história de vida na fazenda. Assim, realizou-se primeiramente um levantamento do patrimônio imaterial que se apresentava nas dezoito fazendas históricas paulistas selecionadas pelo projeto em Políticas Públicas PPPP/FAPESP, através de entrevistas abertas para a rememoração dos saberes tradicionais rurais com os proprietários e também com os funcionários mais antigos em fazendas que estavam realizando atividades educacionais e turísticas no espaço da propriedade.

Para a entrevista, foi elaborado previamente um roteiro de questões, tendo por base a história da propriedade, os itens lendas e causos, festas e comemorações, culinária típica da fazenda, atividades musicais, de artesanato e remédios caseiros feitos à base de plantas. Elas permitiram um conhecimento e crítica das atividades de educação patrimonial e de turismo cultural no espaço rural atuais, objetivando principalmente elaborar sugestões e caminhos para melhor implementá-las.

Para as narrativas, Lang (2001) mostra através de suas experiências de pesquisa, que existem vários tipos com características distintas: o depoimento, a história de vida e o relato de vida. No caso da presente pesquisa para o levantamento do patrimônio imaterial das fazendas históricas paulistas, utilizou-se o relato de vida que a autora caracteriza como:

\footnotetext{
O relato de vida é uma forma menos ampla e livre que a história de vida, dado que é solicitado ao narrador que aborde de modo mais especial determinados aspectos de sua vida, embora dando a ele total liberdade de exposição; o entrevistado sabe do interesse do pesquisador e direciona o relato para determinados tópicos (LANG, 2001, p. 96-97).
}

Dessa maneira, geralmente conseguiu-se colher um depoimento que alternasse rememorações prazerosas do passado, com constatações sofridas da pobreza cultural da vida social contemporânea, nas propriedades históricas visitadas e a manifestação do prazer, que o trabalhador dizia encontrar, ao relatar para crianças e adolescentes, como era o viver nos espaços que eles estavam vindo conhecer. Os trabalhadores entrevistados muitas vezes também falavam da realização que encontravam ao liderar os passeios equestres e as cavalgadas, realizados com os hóspedes pelos caminhos e trilhas da fazenda, que eles tão bem conheciam. 
Lang, Campos e Demartini (2010) afirmam que o documento não fala por si só e precisa ser analisado com vistas à questão do estudo. O trabalho de História Oral não se esgota na realização, gravação, transcrição e arquivamento da entrevista, dado que se orienta para o estudo de um determinado aspecto da realidade social. $\mathrm{O}$ documento resultante da entrevista deve revelar a interação entre os participantes.

Dessa forma, foi imprescindível a utilização de registros em diário de campo, que para Simson e Giglio (2001) é onde estão registrados todos os aspectos da construção da relação entre entrevistador e os vários entrevistados, as percepções e os insigths que aconteceram durante a longa série de contatos e visitas ao campo.

Segundo Meihy e Holanda (2007, p. 152), uma das funções do caderno de campo é possibilitar um diálogo frequente e constante em relação ao projeto inicial. Para os autores, o caderno de campo se torna um referencial obrigatório nas finalizações dos trabalhos em que são registrados até os problemas de aceitação das ideias dos entrevistados, bem como toda e qualquer reflexão teórica decorrente de debates sobre aspectos do assunto.

Thompson (2006) relata em seu artigo "Histórias de Vida como Patrimônio da Humanidade", seu trabalho com o caderno de campo para registrar o que notava durante sua pesquisa com comunidades pesqueiras:

\footnotetext{
Quando estava trabalhando com comunidades pesqueiras na Escócia para meu livro Living the Fishing, eu costumava sentar no bar onde os velhos pescadores estavam, na enseada. Observávamos os barcos chegando e eles me contavam quem estava em cada um deles e também um pouco de suas próprias vidas. Aprende-se muito dessa maneira (THOMPSON, 2006, p. 22).
}

Nesse contexto, pesquisadoras do Centro de Estudos Rurais e Urbanos - CERU da Universidade de São Paulo afirmam:

\footnotetext{
No caderno de campo são anotadas observações do contato e da própria entrevista: o ambiente, a conversação anterior e posterior, novos contatos. Do mesmo modo, é registrada a forma diversa de emoção que cerca a rememoração, como hesitações, silêncios, lapsos, associações, momentos de alegria ou tristeza. Há passagens que o entrevistado narra, mas pede que não sejam gravadas; são anotadas para facilitar o entendimento da entrevista, mas não poderão ser utilizadas, nem disponibilizadas no arquivo (LANG, CAMPOS; DEMARTINI, 2010, p. 44-45).
} 
Além dos proprietários e funcionários mais antigos de cada fazenda selecionada, os turistas, em sua total maioria idosos, foram entrevistados. Foram acompanhadas as visitas feitas pela propriedade junto aos turistas para criar uma maior aproximação e ao final foram agendados outros encontros para a realização da entrevista.

Para a entrevista, foi elaborado previamente um roteiro de questões, tendo por base o significado da viagem para a elevação da qualidade de vida para os idosos, o gosto de conhecer lugares históricos, sugestões para enriquecer a visita realizada, buscando avaliar também se as visitas às fazendas forneciam oportunidades sedutoras de aprendizagem enfocando questões de educação patrimonial, através do turismo cultural, nas quais o turista deixa de vivenciar uma posição passiva para se tornar um visitante ativo envolvido com a realidade a ser conhecida.

Dessa maneira, Lang, Campos e Demartini (2010) reiteram que a História Oral é um processo de construção conjunta entre pesquisador/pesquisado, não havendo receita pronta para a condução de um estudo.

As narrativas orais coletadas no trabalho de História Oral podem assumir formas distintas, mas que no caso das entrevistas com os turistas, utilizou-se o depoimento oral que segundo Lang, Campos e Demartini (2010, p. 45):

\footnotetext{
O depoimento oral constitui uma modalidade bastante diversa das anteriores, à medida que se busca, através dele, obter informações e o testemunho do entrevistado sobre sua vivência em determinadas situações ou a participação em determinadas instituições que se quer estudar.
}

Como aliados a metodologia da história oral, utilizou-se o caderno de campo e as fotografias realizadas in loco. Lang, Campos e Demartini (2010), afirmaram que muitas pesquisas procuram incorporar ou associar outras fontes não verbais para enriquecer o estudo e superar, de certa forma, as limitações de uma amostra reduzida, como é próprio da pesquisa qualitativa. Thompson (2006) afirma que se ganha muito ao misturar os métodos de pesquisa social, em lugar de ficar preso a um único método.

Os suportes não verbais são definidos pela ausência de linguagem verbal e por independência comunicativa ou autonomia em relação a ela, mas como signos que são carregam mensagens e se dão a ler, assim como são portadores de memória e história, como é o caso da fotografia (FERNANDES; LIMA, s./data). Para Mauad (1997, p. 314): 
[...] para se chegar aquilo que não foi imediatamente revelado pelo olhar fotográfico, há que se perceber: as relações entre signo e imagem, aspectos da mensagem que a imagem fotográfica elabora, e principalmente, inserir a fotografia no panorama cultural, no qual foi produzida, e entendê-la como uma escolha realizada de acordo com uma dada visão de mundo [...].

Nesse sentido, é necessário se pensar no turismo como um benefício ao patrimônio cultural e ao mesmo tempo, levar em conta os perigos de uma atividade turística descontrolada. Nesse caso, o turismo cultural passa a desencadear um processo entre passado e presente, com testemunhas vivas, o que foi verificado nessas fazendas históricas, fugindo da ideia dos resorts e da artificialidade que os compõem.

\footnotetext{
Nessas fazendas os proprietários rurais recebem os hóspedes, levam-nos para conhecer todo o funcionamento do lugar, o modo de vida, hábitos e costumes locais e fazem com que as pessoas entrem em contato, interagindo com o meio, seja através de passeios à cavalo, de caminhadas ou da participação nas atividades de plantio e colheita - atividades agrícolas. Um diferencial marcante é que os turistas são acomodados como amigos e vivenciam a experiência como se fizessem parte da família (FAUSTINO, 2006, p. 23).
}

Cabral (2004) chama a atenção para que se leve em conta que o patrimônio é um campo extraordinário onde as pessoas podem vivenciar uma série de experiências, sendo concebido como "campo de educação". A autora ainda ressalta que para preservar o patrimônio, é preciso antes de tudo conhecê-lo, e é por isso que o patrimônio é campo de educação, ou seja, é necessário entender a educação como uma prática para a cidadania, compreendendo-a como a garantia de acesso aos conhecimentos produzidos historicamente pela humanidade e, simultaneamente como formadora de indivíduos críticos, criativos e autônomos, capazes de agir no seu meio e transformá-lo. Cabral (2004) finaliza afirmando que os indivíduos devem ser atores de seu próprio desenvolvimento, partindo daí a discussão do patrimônio a par com a questão do poder e das significações.

Dessa forma, a meta da interpretação sociocultural desse rico patrimônio rural paulista aplicada à atividade turística é estabelecer uma rede de descobertas para o visitante, seja ele proveniente das classes média ou média-alta ou ainda originário das classes populares, estimulando o seu olhar, provocando a sua curiosidade e levando-o a descobrir muito mais sobre o lugar e seus habitantes.

Nesse sentido, a história do tempo presente desses locais, referindo-se ao espaço-tempo de proximidade com os sujeitos viventes, com suas lendas, causos e 
modinhas, passa a valorizar tanto as atrações naturais como as culturais, ainda preservadas nas fazendas históricas.

\section{CONCLUSÃO}

Percebe-se que com o intenso processo de urbanização e avanço do agronegócio tais tipos de propriedades estão em risco de extinção. Dessa forma, a pesquisa possibilitou através da metodologia da história oral, a construção de um conhecimento sobre a cultura material e imaterial e sua utilização em atividades de turismo cultural em espaços rurais privados (as fazendas históricas), anteriormente inacessíveis aos pesquisadores das diferentes disciplinas que integraram a equipe da pesquisa em políticas públicas FAPESP - CMU.

Além disso, trouxe novas contribuições, através de encontros e discussões que envolveram diretamente os proprietários das fazendas históricas, em que a atividade turística passara a representar uma melhoria da qualidade de vida dos visitantes urbanos, ao aumentar as potencialidades de entendimento, via relações intergeracionais e até permitir o desenvolvimento do sentido de pertencimento que conduz à construção da cidadania e à ampliação do conceito de patrimônio cultural através da preservação do patrimônio material e imaterial.

A educação patrimonial é considerada uma questão difícil, considerando a tendência cultural dominante de crise de memória. Nessa perspectiva, a metodologia da história oral possibilitou a preservação da memória e do patrimônio cultural, servindo como um exercício de educação patrimonial, como forma de sensibilizar os visitantes para o compromisso com a memória, com a história e com as próprias ações vivenciadas cotidianamente, na construção da história individual, coletiva e também do tempo presente.

A Educação Patrimonial voltada para o público idoso esclarece e fundamenta o trabalho de conhecimento, apropriação e valorização de diferentes culturas, em diversos lugares e épocas. Embora, consideraram-se terem ficado nítidas, através da fala dos informantes, as diferenças socioeconômicas e culturais entre os diversos grupos observados, a visita à fazenda pareceu representar para todos eles um momento de 
prazer, adquirindo significado de importância para os idosos, porque pôde representar a fuga da rotina e do isolamento ou até a concretização de um sonho, que pela ruptura do cotidiano ampliava horizontes históricos e possibilidades de convivência social.

Dessa forma, é necessário se pensar a educação patrimonial não só como um aspecto a ser trabalhado comumente em escolas, mas também em espaços educacionais não formais, (como é o caso das fazendas históricas selecionadas na pesquisa) e como fonte de ativação da memória social. Mediante a pesquisa de campo realizada e através da análise de depoimentos, propôs-se mostrar a intersecção da memória com a vida social e o tempo presente.

Através da pesquisa finalmente se constatou em situação de visita às fazendas recebendo públicos idosos, o prazer de construir um conhecimento sobre o passado rural que também poderia ser um passado de outras gerações da família, sem restrições curriculares, sem cobranças avaliativas e envolvendo memórias orais partilhadas por várias gerações.

As intervenções feitas pelos proprietários dessas fazendas aperfeiçoam recursos, tanto materiais quanto imateriais, promovendo a participação comprometida e o desenvolvimento social, cultural e educativo dos turistas. Cuidam da recepção dos mesmos, mais centrados na oferta de atividades de educação patrimonial e não apenas na promoção do ócio consumista ou de um enfoque exclusivamente recreativo ou de entretenimento pessoal, possibilitando assim, uma experiência turística em toda sua extensão e não só como mera realização de uma viagem de descanso.

O turismo cultural no espaço rural parte da constatação de que se deve prover atividades turístico-culturais com infraestrutura e facilidades instaladas em propriedades, tanto aquelas de pequenos produtores rurais, como neste caso nas fazendas históricas paulistas selecionadas. Estas são motivadoras e propiciadoras de trabalho para as famílias residentes no campo e geradoras de oportunidades de emprego, enquanto oferecem aos turistas situações originais para desfrutarem do ambiente rural, vivenciando atividades e costumes ausentes do ambiente urbano.

Assim, as experiências das visitas acompanhadas durante o trabalho de campo, demonstraram que a conservação do patrimônio cultural rural pode ser entendida, sobretudo, como uma consequência do turismo cultural e da educação patrimonial não formal. Sendo assim, a atividade turística contribuiu no sentido da valorização da 
cultura rural como um todo, através do patrimônio material (patrimônio arquitetônico) e do imaterial (saberes e fazeres).

As possibilidades de um trabalho de Educação Patrimonial não formal em fazendas históricas paulistas promovem a ativação da memória social, construindo a autoestima principalmente dos idosos, de modo a se identificarem com o patrimônio e o valorizarem como um bem de toda a coletividade.

A pesquisa sobre o Patrimônio Cultural Rural Paulista por meio da metodologia da história oral, se tornou um trabalho sobre a utilização dos bens culturais como fonte de lazer e turismo, possibilitando um exercício de sensibilização para a valorização dos espaços rurais, a partir da análise das representações dos sujeitos e seus papéis, o imaginário rural, e da decodificação dos valores existentes naquele espaço.

\section{REFERÊNCIAS}

AFONSO, A. Sociologia da educação não formal: Reactualizar um objecto ou construir uma nova problemática? In: ESTEVES, A. J; STOER, S. R. A sociologia na escola. Porto: Afrontamento, 1989.

ALMEIDA, M. Prefácio. In: PAES, M. T. D; OLIVEIRA, M. R. S. (orgs.). Geografia, Turismo e Patrimônio Cultural. São Paulo: Annablume, 2010.

BARRETTO, M. Turismo e Identidade Local: Uma visão antropológica. Campinas, (SP): Papirus; 2001.

CABRAL, M. Memória, patrimônio e educação. In: Resgate: Revista de Cultura, p. 35-42, n. 13. Campinas (SP): Centro de Memória UNICAMP, 2004.

DAVIS, K. Biography as critical methodology. In: Newsletter Research Committee of ISA, n. 38, Utrecht University, 2003.

DEBERT, G. A construção e a reconstrução da velhice: família, classe social e etnicidade. In: NERI, A.; DEBERT, G. (orgs.). Velhice e sociedade. Campinas (SP), Papirus; 1999.

FAUSTINO, R. O turismo em espaço rural como modo de valorização do Patrimônio Cultural: estudos de caso na média depressão periférica paulista: o caso das Fazendas Capoava e Ibicaba [tese - doutorado]. São Paulo (SP). Programa de PósGraduação em Geografia. Faculdade de Filosofia, Letras e Ciências Humanas. Universidade de São Paulo/ USP, 2006. 
FERNANDES, R. S; LIMA, L. M. G. A metodologia da história oral ou da história falada na pesquisa em educação não formal ou sociocomunitaria. Campinas: Ed. Papirus, no prelo, (s./data).

GARCIA, V. A. A educação não formal como acontecimento. [Tese de doutorado]. Programa de Pós-Graduação em Educação. Faculdade de Educação - Universidade Estadual de Campinas. Campinas/ UNICAMP. 2009.

HALBWACHS, M. A memória coletiva. São Paulo (SP): Vértice; 1990.

LANG, B. G. História Oral: procedimentos e possibilidades. In: Desafios da pesquisa em Ciências Sociais. Texto 8, v. 2. São Paulo: CERU, p. 91-112, 2001.

LANG, B; CAMPOS, M. C; DEMARTINI, Z. Historia Oral, Sociologia e Pesquisa: a abordagem do CERU. São Paulo: Humanitas, 2010.

MARINS, P. Preservação do patrimônio rural no Estado de São Paulo: entre ação governamental e práticas sociais. In: CORREIA, T; BORTOLUCCI, M A. (orgs.). Lugares de produção: arquitetura, paisagens e patrimônio. São Paulo: Annablume, 2013.

MAUAD, A. M. História, iconografia e memória. In: SIMSON, O. R. M. (org.). Os desafios contemporâneos da História Oral. Campinas, SP: Editora da Unicamp/ Centro de Memória, p. 309-320, 1997.

MEIHY, J; HOLANDA, F. Historia Oral: como fazer, como pensar. São Paulo: Contexto, 2007.

OLIVEIRA, G. Gestão e vivências de velhices nas Repúblicas de Idosos de Santos [dissertação - mestrado]. Programa de Pós-Graduação em Antropologia. Faculdade de Filosofia, Letras e Ciências Humanas. Universidade de São Paulo. São Paulo/USP; 2009.

PARK, M. B.; FERNANDES, R. S. Educação não formal: contextos, percursos e sujeitos. Campinas, SP: Unicamp/CMU; Holambra, SP: Editora Setembro, 2005.

PARK, M. B.; FERNANDES, R. S.; CARNICEL, A. Palavras-chave em Educação não formal. Campinas, SP: Editora da Unicamp/Centro de Memória/Editora Setembro, 2007.

PORTELli, A. O que faz a história oral diferente. In: Projeto História: Revista do Programa de Estudos Pós-Graduados em História e do Departamento de História da PUC-SP. (Pontifícia Universidade Católica de São Paulo). São Paulo: 1997.

SIMSON, O.; PARK, M.; FERNANDES, R. S. Educação não formal: Cenários da criação. Campinas (SP): Editora da UNICAMP/Centro de Memória; 2007. 
SIMSON, O; GIGLIO, Z. A arte de recriar o passado: história oral e velhice bemsucedida. In: NERI A. L. (org.). Desenvolvimento e Envelhecimento: Perspectivas Biológicas, Psicológicas, Sociológicas. Campinas (SP): Papirus; 2001.

TEIXEIRA, M. F; TEIXEIRA, S. K. Festividades: representações simbólicas no turismo brasileiro. In: Revista Turismo e Sociedade. Curitiba, v. 7, n. 1, p. 118-134, janeiro de 2014. Não encontrada no texto.

TOGNON, M. Patrimônio: entre passado e presente. In: PARK, M. B. (org). Formação de Educadores: memória, patrimônio e meio ambiente. Campinas - SP: Mercado de Letras, 2003.

TOGNON, M. Patrimônio Cultural Rural Paulista: espaço para pesquisa, educação e turismo (oitava chamada para o Programa de Pesquisas em Políticas Públicas da FAPESP - PPPP/2007). Cidade Universitária Zeferino Vaz, Campinas, SP: Centro de Memória - UNICAMP; Relatório Final FAPESP, 2007.

THOMPSON, P. Histórias de Vida como Patrimônio da Humanidade. In: HISTÓRIA FALADA: memória, rede e mudança social. SESC SP: Museu da Pessoa: Imprensa Oficial do Estado de São Paulo. São Paulo: 2006.

Recebido em: 21-08-2014.

Aprovado em: 20-09-2014. 